\title{
Patterns of Play in the Counterattack of Elite Football Teams - A Mixed Method Approach
}

Hugo Sarmento ${ }^{1,2}$, M. Teresa Anguera ${ }^{3}$, Antonino Pereira ${ }^{1}$, Adilson Marques ${ }^{4}$, Jorge Campaniço ${ }^{5}$ and José Leitão ${ }^{5}$

${ }^{1}$ Polytechnic Institute of Viseu, Centre for the Study of Education, Technologies and Health (Portugal)

${ }^{2}$ High Institute of Maia (Portugal)

${ }^{3}$ University of Barcelona (Spain)

${ }^{4}$ University of Lisbon

${ }^{5} \mathrm{UTAD}$ (Portugal)

\begin{abstract}
This study aimed to detect and analyse regular patterns of play in football teams during their offensive phase, through the combination of the sequential analysis technique and semi-structured interviews of experienced first League Portuguese coaches.

The sample included 36 games (12 per team) of the F.C. Barcelona, Internazionalle Milano, and Manchester United teams that were analysed through sequential analysis with the software SDIS-GSEQ. Based on the detected patterns, semi-structured interviews were carried out with 8 expert high-performance football coaches. Data were analysed through the content analysis technique using the software Nvivo 9.

The detected patterns of play revealed specific characteristics of different philosophies of play. Through the performed content analysis we could observe that coaches interpreting play patterns mainly based their opinions on tactical-strategic and tactical-technical aspects, and on the characteristics of the players on their team.

On the other hand, consideration was given to three of the main evolutionary trends of play/soccer practice, which focus on the development of exercises that cover: i) the connection between the four play moments (offensive/defensive organization and transitions); ii) the pre-programmed ball possession recovery; iii) the execution of set pieces.
\end{abstract}

Key words: Soccer, Coaching, Mixed Methods, Performance 


\section{Introduction}

Football is the most famous sport in the world (Pollard \& Reep, 1997; Reilly, 1996), being practiced in every country, with no exception (Reilly, 1996). Despite its popularity, it was only in the last decade that the number of studies with this particular game as the main subject has significantly increased. This investigation boost was substantiated mostly through studies which focused on the description and explanation of physical and/or physiological characteristics, or in the quantification of performed actions in an attempt to quantify the football players' activity (Gregson, Drust, Atkinson, \& Di Salvo, 2010; Lago-Peñas \& Lago-Ballesteros, 2011; Lago-Peñas, LagoBallesteros, \& Rey, 2011; O’Donoghue, 2002; O’Donoghue et al, 2005).

These types of studies, which have been based on the analysis of the frequency of certain performance parameters, provide important information for coaches and athletes, enabling advances in training processes. However, the game of football is characterized by great complexity, which makes it difficult to objectify its observation and analysis (Sarmento, Barbosa, Campaniço, Anguera, \& Leitão, 2013).

For the purpose of overcoming usual limitations found in strictly qualitative investigations, an increase in the amount of research on game action in football has been observed, based on observational methodology and through various methodological procedures, such as sequential analysis (Fernandez, Camerino, Anguera, \& Jonsson, 2009; Lapresa, Álvarez, Arana, Garzón, \& Caballero, 2013; Lapresa, Arana, Anguera, \& Garzón, 2013) and T-patterns analysis (Bloomfield, Jonsson, Polman, \& O`Donoghue, 2005; Camerino, Chaverri, Anguera, \& Jonsson, 2012; Lapresa, Anguera, Alsasua, Arana, \& Garzón, 2013; Sarmento, Barbosa, Anguera, Campaniço, \& Leitão, 2013).

Despite the fact that football is an arbitrary game and partially determined by chance, this kind of analysis, when it is focused in the sequence of events, allows for the detection of behaviour sequences (play patterns), which have higher probabilities of occurrence than mere chance. These become of relevant importance to game analysis.

Trying to predict future performance on the basis of previous performances is an important goal for notation analysts. Typically, the basis for any prediction model is that performance is repeatable, to some degree. In other words, events that have previously occurred will occur again in some predictable manner. This type of prediction is based on the principle that any performance is a consequence of factors like prior learning, inherent skills, and situational variables (James, 2012). In order to detect regular structures of behaviour, sequential analysis has already been used to establish playing patterns in football (Castellano-Paullis \& Hernández-Mendo, 2000; Lapresa, àlvarez, Arana, Garzón \& Caballero, 2013). The basic premise here is that the interactive flow or chain of behaviour is governed by structures of variable stability which can be visualized by detecting these patterns.

Taking into account the aforementioned, one begins to understand the importance of analysing and spotting game patterns in the scope of football analysis, making this a productive path to follow. Nevertheless, the investigation will improve when performed 
in collaboration with the professionals in the field. Since coaches play a crucial role in the game, it seems pertinent to focus on studies where coaches can actively participate, contributing their knowledge and experience for a deeper understanding of the performance of players and teams (Sarmento, Pereira, Campaniço, Anguera, \& Leitão, 2013; Sarmento, Pereira, Matos, et al., 2013).

Despite the stated importance, studies which focused on the analysis of a football game, using qualitative methodologies to examine the opinions of coaches, are still rare (Sarmento, Pereira, Campaniço, Anguera, \& Leitão, 2013; Sarmento, Pereira, Matos, et al., 2013). As stated by O’Donoghue (2010), performance analysis methods can identify some particularities in a specific context but, in others, they cannot explain them. Consequently, the use of interviews with coaches and/or athletes can be valuable to explain certain aspects of performance. Specifically, the author suggests that once a quantitative performance analysis investigation has produced results, an interview with an expert coach can be used to find explanations for the observed behaviour pattern.

As stated by Anguera, Camerino and Castañer (2012) over the past decade, the tendency in favour of the quantitative approach to the study of sport science has gradually given way to a more balanced view (Heinemann, 2003), one in which neither quantitative nor qualitative methods are regarded as inherently better. Each of these methodological perspectives is considered to offer a different way of understanding and approaching the study of physical activity and sport.

Therefore, the aim of this study was to detect and analyse regular sequences of behaviour (patterns of play) on the counterattack of the Internazionale Milano (MI), Manchester United (MU) and Barcelona (BA) football teams, and to subsequently carry out an analysis of these patterns by conducting semi-structured interviews with professional soccer coaches.

\section{Methods}

\subsection{Participants}

A mixed method design (QUAN/QUAL) was used in this study (Anguera et al., 2012). In the first stage, 36 games (12 per team) from the sporting season 2009/2010 of the F.C. Barcelona, Internazionale Milano and Manchester United teams were utilized. These teams were chosen for this study because they won their respective leagues in the season prior to the data collection. The English, Italian, and Spanish Leagues are considered, by the International Federation of Football History and Statistics (IFFHS), to be the three strongest European Leagues of the $1^{\text {st }}$ Decade of the $21^{\text {st }}$ Century. Subsequently, 8 expert high-performance Portuguese first league football coaches (Coach 1 to Coach 8) with professional experience (as first coach) ranging from 2 to 30 years $(14.9 \pm 8.6$ years $)$ were chosen to take part in semi-structured interviews. All coaches, who were initially selected to participate in the study and who accepted the invitation, were coaching professionally at the time the interviews were conducted, and have worked as Head coaches in the Portuguese League. 
Because of the in-depth character of each interview, the interpretational nature of the analysis, and the number of the teams in the first league $(n=16), 8$ coaches were considered to be representative and sufficient to meet the objectives of the study, as well as the criteria of expert selection (previous experience as Head coach in the first Portuguese League; UEFA Pro licensed coach).

\subsection{Instruments}

\subsubsection{Observational Instrument}

The matches were analysed through systematic observation by using a specific instrument to observe the offensive process (Sarmento et al. 2010). The following criteria were used in this study: 1- Type of attack - counter-attack (CA); 2-Start of the Offensive Process (OP) - recovery of ball possession by: interception (IPi); disarm (IPd); goalkeeper action (Ipgr), opponent's goal (Ipga); due to the rules of the game (Ipera); 3- End of the OP - Shot with goal scored (Fgl), shot (Fre), free kick (Fld), corner kick (Fpc), penalty (Fgp), pass inside the penalty area (Fpga), recovery of the ball by the opponent without reaching the penalty area (Fbad), pass to the outside of the field (Ff), violation of the rules of the game by the observed team (Fld); 4-Area where the action was performed - 12 zones and four sectors were differentiated on the field (figure 1); 5-Interactions contexts in the centre of the game (CG).

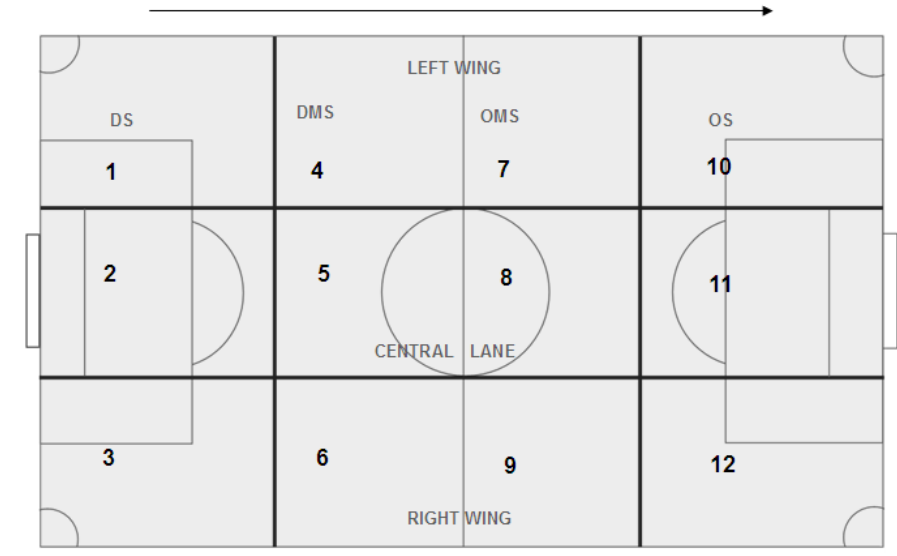

Figure 1. Field of the Game

To analyse the interaction context, we used the concept of the centre of the game (Castelo, 2009), which is defined as the zone of the field where the ball moves in a certain instant, through a context of cooperation and opposition of the influential players in the game, in the specific zone where the player has possession of the ball. We consider 5 categories for this concept: 1- Relative numeric inferiority (Pir): the observed team has a negative difference of 1 or 2 players in the CG (e.g., 1vs2, 3vs5); 2Absolute numeric inferiority (Pia): the observed team has a negative difference of 3 or more players in the CG (e.g., 1vs4, 2vs5); 3-Absolute numeric superiority (SPsa): the observed team has a positive difference of 3 or more players in the CG (e.g., 4vs1, 5vs2); 4- Relative numeric superiority (SPsr): the observed team has a positive difference of 1 or 2 players in the centre of the game (e.g., 2vs1, 2vs0); 5- Equal numeric under pressure (Pip): i) the observed team has the same number of the players 
in the defensive midfield; ii) in the offensive midfield sector, the player in possession of the ball is standing with his back to the goal with an opponent in contention and doesn't have pass lines to areas of greater offensiveness; 6- Equal numeric unpressured (SPinp): the observed team has the same number of players in the offensive sector, or, when in the offensive midfielder sector, the player in possession of the ball is standing with his back to the goal with free pass lines to areas of greater offensiveness, or the player in possession of the ball is facing the goal.

\subsubsection{Interview Guide}

To access the opinion of the coaches, semi-structured interviews were used (Bardin, 2008; Flick, 2005). The interview guide was designed to identify the most relevant issues for the coach so that a further in-depth exploration could be done. The certification of the content validity of the interview was done according to common qualitative research methods (Strauss \& Corbin, 1990). More specifically, it was attained after preparation and discussion of previous drafts of the transcript, based on the following steps: i) preparation of a first draft of the transcript based on the specific aims of the study and available literature, ii) evaluation of the interview transcripts by three senior researchers in sports pedagogy, who have substantial experience with qualitative methods, iii) discussion of findings based on the presented suggestions by each, iv) a pilot study done with a Portuguese first league coach, v) minor adaptations to the transcripts resulting from the reflections of the pilot study, and vi) resubmission of the updated version of the transcripts to the experts. These steps ultimately resulted in the final version of the interview guide.

\subsection{Data Collection}

\subsection{1 - Quantitative data}

To codify the offensive sequences, the specific recording instrument developed by Sarmento et al. (2010) was used. This is a user-friendly tool developed to help researchers observe, codify, register, and analyse the offensive process in football. After recording each game, we obtained an Excel file comprising the successive configurations formed by the lines of codes that changed, along with their time placement and duration expressed in frames ( 25 frames is equivalent to $1 \mathrm{sec}$ ). The reliability of data was calculated by the intra and inter observer agreement (Cohen's Kappa), and values above 0.90 for all criteria were achieved: i) Type of attack (0.99, 0.97, intra-observer agreement and inter observer agreement, respectively); ii) Start of the offensive process $(0.94,0.91)$; iii) Development of the OP $(0.99,0.98)$; iv) End of the OP $(0.96,0.95)$; v) Area where the action was performed $(0.96,0.93)$; vi) Interaction contexts in the centre of the game $(0.93,0.91)$.

\subsubsection{Qualitative data}

All the interviews were done by the first author, between December 2011 and February 2012, in a relaxed setting (normally in the office) at the football academies where the different coaches work. The interview began by stating the general information about the purpose of the project. Next, the interviewer focused on background and demographic information. And finally, a more in-depth exploration of the topic followed. None of the interviews were rushed, and the coaches had time to clarify and 
reformulate their thinking. Each interview took between 1 and $2 \frac{1}{2}$ hours and was transcribed verbatim (93 pages).

\subsection{Data analysis}

\subsubsection{Sequential analysis}

The data was analysed through sequential analysis (Bakeman \& Gottman, 1989) that consists of a set of techniques that aim to emphasize relationships, associations, and dependencies between sequential units of conduct. This type of analysis assesses the probability of occurrence of certain behaviours, depending on the prior occurrence of others, based on the analysis of the adjusted residuals calculated by means of lag sequential analysis (only the $\mathrm{Z}_{\text {score }}$ values above 1.96 were considered significant). It intends to show a sequential order (i.e., a stability in the succession of sequences, which is above the odds that are explainable by chance).

In sequential analysis two types of conduct (behaviour) should be considered: 1) given behaviour, which is the category, in the sequence data, which needs to account for transitions or lags on a prospective (forward, $\mathrm{R}+1, \mathrm{R}+2 \ldots$ ) or retrospective (back, $\mathrm{R}-1$, $\mathrm{R}-2 \ldots$ ) way, and; 2) target behaviour, which is the category, in the sequence data, which needs to account for transitions/lags. In this paper we will use the prospect of these two analyses, according to the logic of the game (until the lags, $R+5$ and $R-5$ ). To analyse the data, the software SDIS-GSEQ 5.0 was used.

\subsubsection{Content data analysis}

The objective of the content data analysis was to build a system of categories that emerged from the unstructured data and that represented the organization and utilization of an expert high-performance football coach's view of the topic.

Data analysis was performed using content analysis (Bardin, 2008), and through combining inductive and deductive approaches, the text units were coded; text units with comparable meanings were organized into specific categories. Three researchers conducted the analysis independently to ensure that the resulting classification system was suitable and best fitted the data. The software QSR NVivo 9 was used in coding the transcripts of the interviews.

The initial data analysis revealed 7 categories concerning the coaches' pattern analysis. These were grouped into 3 final categories.

\section{Results}

Taking into account that the present study has chosen to apply two methodologies (sequential analysis and qualitative content analysis), with the purpose of complementing the analysis made to the counterattack patterns of the teams in the study, we opted to present the results in two parts. In the first part, we present the descriptive statistics values and the results of the categorization system resulting from the qualitative content analysis. In the second part, we presented, in an integrated and 
complementary way, the data from the sequential analysis together with the most significant sentences stated by the coaches.

\subsection{Quantitative data}

In the 32 matches observed, 245 counterattack sequences were coded, consisting of 126 counterattacks for Manchester United, 65 for Barcelona and 54 for Internazionale de Milano. The Chi-square test $\left(\mathrm{X}^{2}(2)=36.8 ; \mathrm{p}=0.000 ; \mathrm{n}=245\right)$ reveals that the MU team performed significantly more counterattacks than the other two teams. This result is in accordance with studies carried out by Hughes and Franks (2005), and Sarmento et al. (2013) in which they claim that the tactics of "direct play" still permeate the manner in which most clubs play in Britain.

\subsection{Content analysis}

After identifying counterattack patterns, the coaches were asked to perform an analysis of these play regularities through a semi-structured interview, and the resulting data was then analysed through content analysis technique. From this analysis three central categories emerged and embodied mainly the tactical-strategic aspects $(n=95)$, the tactical-technical aspects $(n=44)$ and the specific characteristics of the players $(n=44)$.

\subsection{Combined results of sequential analysis and qualitative data}

The analysis of the results concerning the start of the offensive process, through ball recovery possession by the goal keeper (GK), verifies that with Manchester United (table 1 and figure 1), there is a tendency for these attack sequences to be developed through the defensive central zone (zone 2), and through both the right side zones of the defensive midfielder (zone 3 and 6), via the execution of the forward pass (Pfr).

Barcelona (table 1 and figure 2) demonstrated a tendency towards offensive sequences that were observed to be developed mainly in the central areas (zones 2 and 5), and in the right side zone of the defensive midfielder (zones 6), by the execution of technical actions such as dribble (Ddr) and conduction of the ball (Dcd). This allowed for a quick transition from defence to offence, in an attempt to take advantage of favourable interaction contexts characterized by numerical equality (pip). The analysis of this interaction context, in which the sports behaviours are produced, offers important information for game analysis as stated by O’Donoghue (2009) and McGarry (2009).

On the other hand, the analysis of the IM data (see figure 3) has served to verify several regularities that distinguish this team from the other two. After the ball recovery possession by the GK, the ball reposition is performed using a long (Dpl) and high (Pal) pass, probably with the purpose of exploring the advance of the opponent team lines, and also probing the possible lack of organization from the opposing team, allowing for a quick transition to the offensive midfielder (zones 8 and 11). This differs from what seems to be the practice in BA and IM teams as previously described. 
Table 1 - Adjusted Residuals calculated by Means of Lag Sequential Analysis ( $\mathrm{R}+1$ to $\mathrm{R}+5$ ) using the given behaviours of the start of the offensive process

\begin{tabular}{|c|c|c|c|c|c|}
\hline \multirow[b]{2}{*}{ Ball recovery possession } & \multicolumn{5}{|c|}{ Barcelona } \\
\hline & $\mathbf{R + 1}$ & $\mathbf{R}+\mathbf{2}$ & $\mathbf{R}+3$ & $R+4$ & $\mathbf{R}+5$ \\
\hline $\begin{array}{l}\text { Interception of the ball } \\
\text { (Ipi) }\end{array}$ & --- & --- & --- & --- & --- \\
\hline Disarm (Ipd) & $\begin{array}{l}\operatorname{Ddr}(2.24) \\
\operatorname{Pfr}(2.02)\end{array}$ & Z9 (2.20) & Z9 (2.56) & -- & $\begin{array}{l}--- \\
---\end{array}$ \\
\hline $\begin{array}{l}\text { Goal keeper action } \\
\text { (Ipgr) }\end{array}$ & $\begin{array}{l}--- \\
\mathrm{Z} 2(5.52) \\
---\end{array}$ & $\begin{array}{l}\text { Ddr (2.47) } \\
\text { Z6 (2.55) } \\
\text { Pip (1.96) }\end{array}$ & $\begin{array}{l}\text { Dcd (2.71) } \\
\text { Z6 (2.15) }\end{array}$ & $\begin{array}{l}--- \\
\text { Z5 (3.42) } \\
---\end{array}$ & $\begin{array}{l}--- \\
--- \\
---\end{array}$ \\
\hline \multirow[t]{3}{*}{$\begin{array}{l}\text { Due to the rules of the } \\
\text { game (Ipera) }\end{array}$} & $\begin{array}{l}\operatorname{Drc}(2.58) \\
-- \\
\operatorname{Pir}(2.83)\end{array}$ & Z12 (2.34) & $\begin{array}{l}--- \\
\text { Z7 (3.09) } \\
---\end{array}$ & $\begin{array}{l}--- \\
\text { Z7 (2.37) } \\
---\end{array}$ & --- \\
\hline & \multicolumn{5}{|c|}{ Inter de Milão } \\
\hline & $\mathbf{R}+1$ & $\mathbf{R}+2$ & $\mathbf{R}+\mathbf{3}$ & $R+4$ & $\mathbf{R}+5$ \\
\hline $\begin{array}{l}\text { Interception of the ball } \\
\text { (Ipi) }\end{array}$ & $\operatorname{Dcd}(2.01)$ & --- & --- & --- & --- \\
\hline Disarm (Ipd) & $\begin{array}{c}\operatorname{Ddr}(2.78) \\
-----\end{array}$ & $\begin{array}{l}\operatorname{Dcz}(2.02) \\
\text { Z4(2.51) } \\
\text { Z12(1.99) }\end{array}$ & --- & --- & --- \\
\hline $\begin{array}{l}\text { Goal keeper action } \\
\text { (Ipgr) }\end{array}$ & $\begin{array}{l}\text { Dpl (2.74) } \\
\text { Dia (2.74) } \\
\text { Pal (3.16) } \\
\text { Z1 (2.74) }\end{array}$ & $\begin{array}{l}\text { Dia (2.06) } \\
\text { Z8 (1.99) }\end{array}$ & $\begin{array}{l}--- \\
\text { Z8 (2.08) } \\
\text { Z11 (2.06) }\end{array}$ & Z8 (2.48) & Z8 (2.36) \\
\hline \multirow[t]{3}{*}{$\begin{array}{l}\text { Due to the rules of the } \\
\text { game (Ipera) }\end{array}$} & $\begin{array}{l}\text { Drc (2.01) } \\
\text { Pma (4.58) } \\
\text { Rjl (2.37) } \\
\text { Pir (3.29) }\end{array}$ & Dpc (2.20) & Dre (2.11) & & \\
\hline & \multicolumn{5}{|c|}{ Manchester United } \\
\hline & $\mathbf{R}+1$ & $\mathbf{R}+2$ & $\mathbf{R}+\mathbf{3}$ & $R+4$ & $\mathbf{R + 5}$ \\
\hline $\begin{array}{l}\text { Interception of the ball } \\
\text { (Ipi) }\end{array}$ & Z8 (2.39) & $\mathrm{Z8}(2.28)$ & --- & --- & --- \\
\hline $\begin{array}{l}\text { Disarm } \\
\text { (Ipd) }\end{array}$ & $\begin{array}{l}\text { Pip (2.52) } \\
\text { Z10 (2.23) }\end{array}$ & --- & $\begin{array}{l}\text { Spsr (2.14) } \\
\text { Z9 (2.86) }\end{array}$ & $\begin{array}{l}--- \\
\text { Z12 (2.17) }\end{array}$ & $\begin{array}{l}--- \\
---\end{array}$ \\
\hline $\begin{array}{l}\text { Goal keeper action } \\
\text { (Ipgr) }\end{array}$ & $\begin{array}{l}--- \\
\text { Z2 (2.92) } \\
\text { Z3 (5.26) } \\
---\end{array}$ & $\begin{array}{l}\text { Pfr (2.00) } \\
\text { Z6 (2.08) } \\
\text { Pip (4.18) }\end{array}$ & $\begin{array}{l}--- \\
\text { Z6 (2.73) }\end{array}$ & $\begin{array}{l}--- \\
\text { Z6 (3.35) }\end{array}$ & Z6 (2.30) \\
\hline $\begin{array}{l}\text { Due to the rules of the } \\
\text { game (Ipera) }\end{array}$ & $\begin{array}{l}\text { Drc }(2.20) \\
\text { Dia }(2.98) \\
--- \\
---\end{array}$ & $\begin{array}{l}\text { Ddu (2.84) } \\
\text { Z7 (2.08) } \\
\text { Z9 (2.06) } \\
\text { Spinp (4.45) }\end{array}$ & $\begin{array}{l}\text { Dcz (2.39) } \\
--- \\
---\end{array}$ & $\begin{array}{l}--- \\
--- \\
---\end{array}$ & $\begin{array}{l}--- \\
--- \\
---\end{array}$ \\
\hline
\end{tabular}

The analyses produced by the coaches with regard to these characteristics were based, in part, on the game model and game principles, but mainly on the players' characteristics.

"This has, very often, something to do with the principles of the game. Several times, it has to do with the players' characteristics. Who does Barcelona have on the right side? Daniel Alves. In Manchester United, the lateral defenders are also offensives; very often they attack both simultaneously, because there are compensations in the central areas for these players. This is why I believe that 
many times it is related with the specific behaviour of the teams, which can be trained." (Coach 1)

"I think it has to do with the individual characteristics of each player, with their game model, and also with game strategy. Barcelona plays with Messi going inside, this dynamic makes defences keep up with him, leaving this side of the field without players, so Daniel Alves can come forward. Therefore, there is a tendency to let the game flow through this area of the field." (Coach 7).

The results suggest that ball recovery possession using interception leads to great variability among the MU teams' behaviours, while in IM, this ball recovery possession activates the development by conduction of the ball (Dcd). We suppose that this conduction of the ball is performed by the same player who intercepts the ball in an attempt to progress to areas of more offensiveness; looking to take advantage of the lack of organization of the opponent's defence.

Other results are linked with the fact that, in counterattack, the ball recovery situations by disarm are followed by technical gestures such as dribble (BA) and crossing (BA and IM) in zones of the offensive midfielder. The interviewed coaches highlighted the importance of disarm as a way of recovering the ball since it allows teams to take advantage of the lack of defensive organization of their opponents.

"It is basically because of one thing. Because the opponent needs to change from an offensive attitude to a defensive attitude, and normally, it is in these moments that the probabilities or possibilities of success in offensive actions increase." (Coach 3)

"The disarming usually occurs when a team wins ball possession, and usually in these moments the players of the other team are "more open in the field", spread out in the area, this is why there is a certain area that might be used by the opposing team. This is also why, many times the ball is recovered in an advanced area, in an intermediary area of the opposing team's field, there is a pass, a quick conduction of the ball to a far ahead positioned player. Immediately 6 or 7 players from the opposing team became completely out of the play, and there is a need to make the most out of this brief unbalance we were able to create." (Coach 1) 


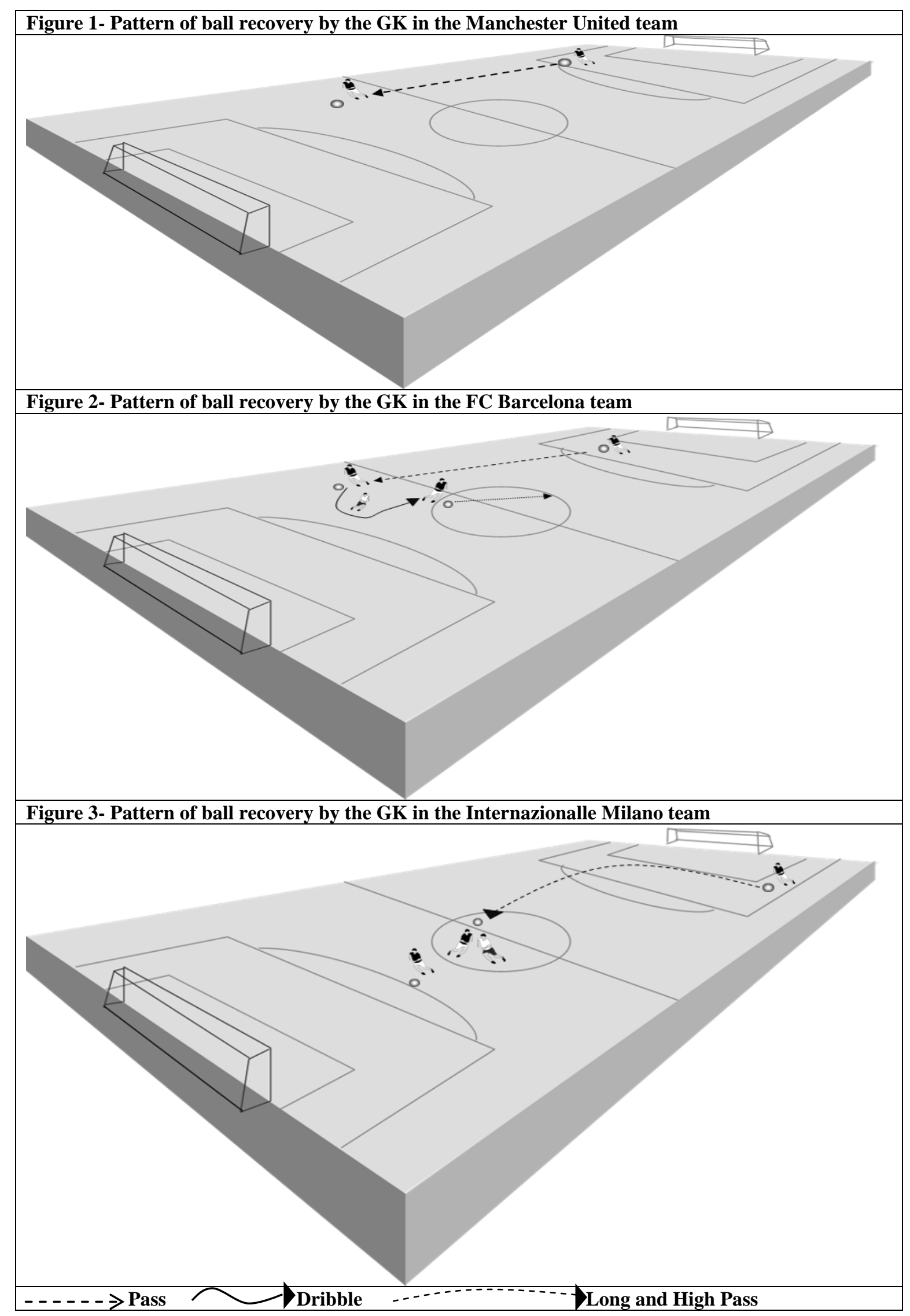


The sequential analysis has led to the conclusion that regular interruptions in favour, such as throw-ins or faults, activate behaviour like the crossing (Dcz) in MU team or shot (Dre) in IM. This means that actions of higher offensiveness might cause "disturbances" in the opposing team.

Coaches have considered these moments in the game privileged, because teams can make the most out of their opponent's lack of defensive organization by performing the quick execution of faults, and throw-ins, or by displacing influential players towards those areas to enhance their characteristics. According to the interviewed coaches, it is easy to create automated processes through the execution of these interruptions due the laws of the game and the practice of the appropriate training exercises.

"Yes, teams seem to take more advantages of these moments more often. On top of it, these are easy situations for training. Create automatic reactions towards these moments. It is much easier than conceiving them for other moments in the game." (Coach 4)

"I believe that the execution of these interruptions, due to the rules of the game, is important. There is a huge tendency for people to restrict the set pieces to the last third of the field. I say no! Meaning that, the set pieces must be set up independently of the fact that it is near my goal or the opposing team's goal. It is why during the training session, all throw-ins and free kicks are performed in the same way as in the competition." (Coach 5)

Concerning the results obtained from the retrospective sequential analysis, following (as criteria behaviour) the shot with goal scored (see table 2, and figures 4, 5 and 6) we have concluded that in BA team, this pattern is activated by the crossing (Dcz), the high (Pal) diagonal pass to the back (Pdt) and by areas belonging to the offensive sector (zone 10,11 and 12) when in numeric inferiority (Pir).

The pattern observed for MU leads us to believe that there are "barriers" which the team cannot overcome with the same efficiency as the BA team. This can be justified by the opponents' failed intervention (Dia), by the fact that the goal scored was preceded by a failed shot (Dre), and by an action performed by the goal keeper.

Normally, and contrary to what happens with the other teams (IM and BA), the goal tends to be activated by areas of the central offensive midfield ( 8 and 11) and by zone 4 . 
Table 2 - Adjusted Residuals calculated by Means of Lag Sequential Analysis (R-1 to $\mathrm{R}-1$ ) using the given behaviours of the start of the offensive process

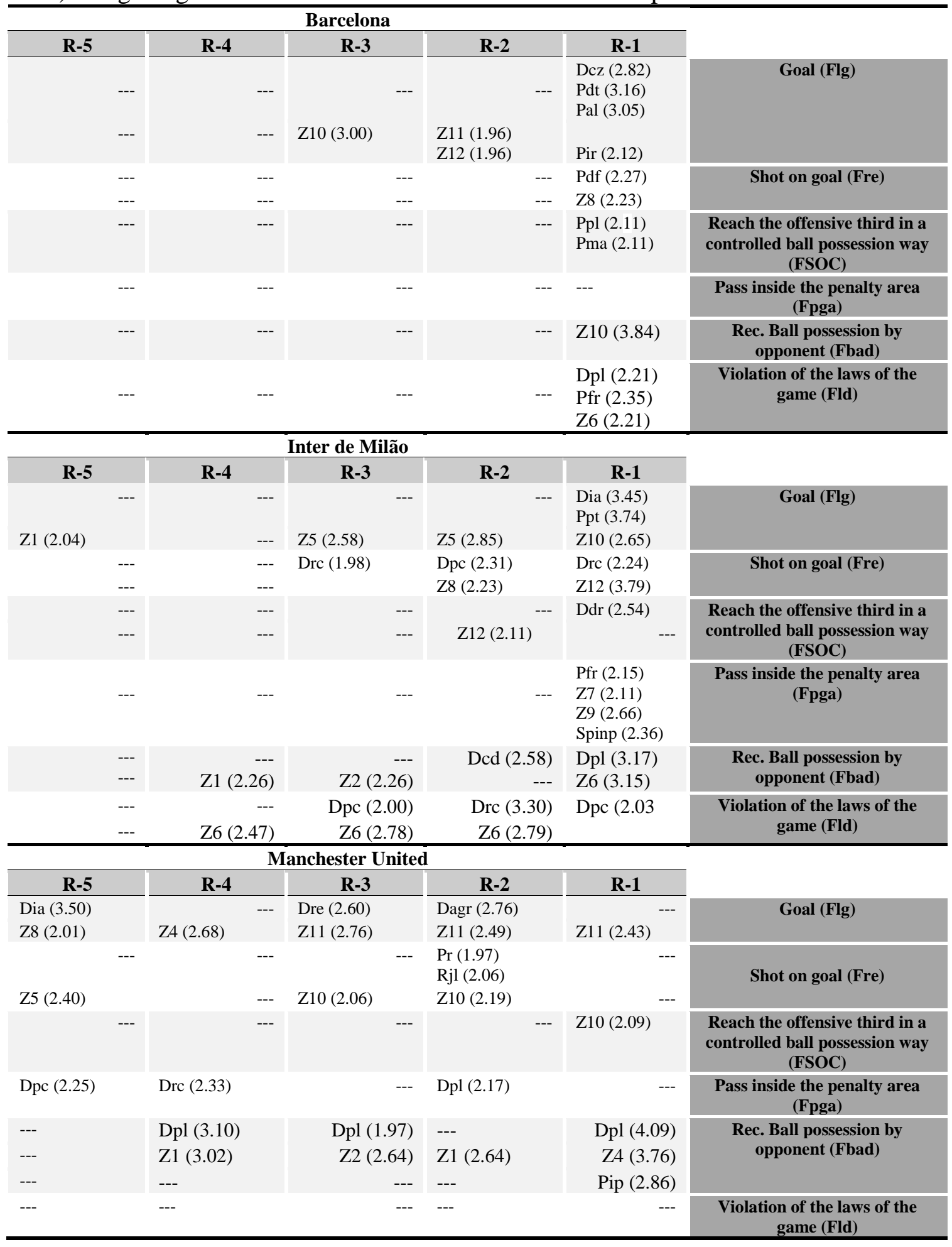

An interesting point comes from the analysis performed on IM data, and it is related to the fact that the goal is being activated by the defensive midfield areas (zone 1 and 5). Therefore, before the shot with goal scored, the ball comes from within these areas, 
following situations where there is either a failed intervention of the opponent or a pass to the back $(\mathrm{Ppt})$ in zone 10.

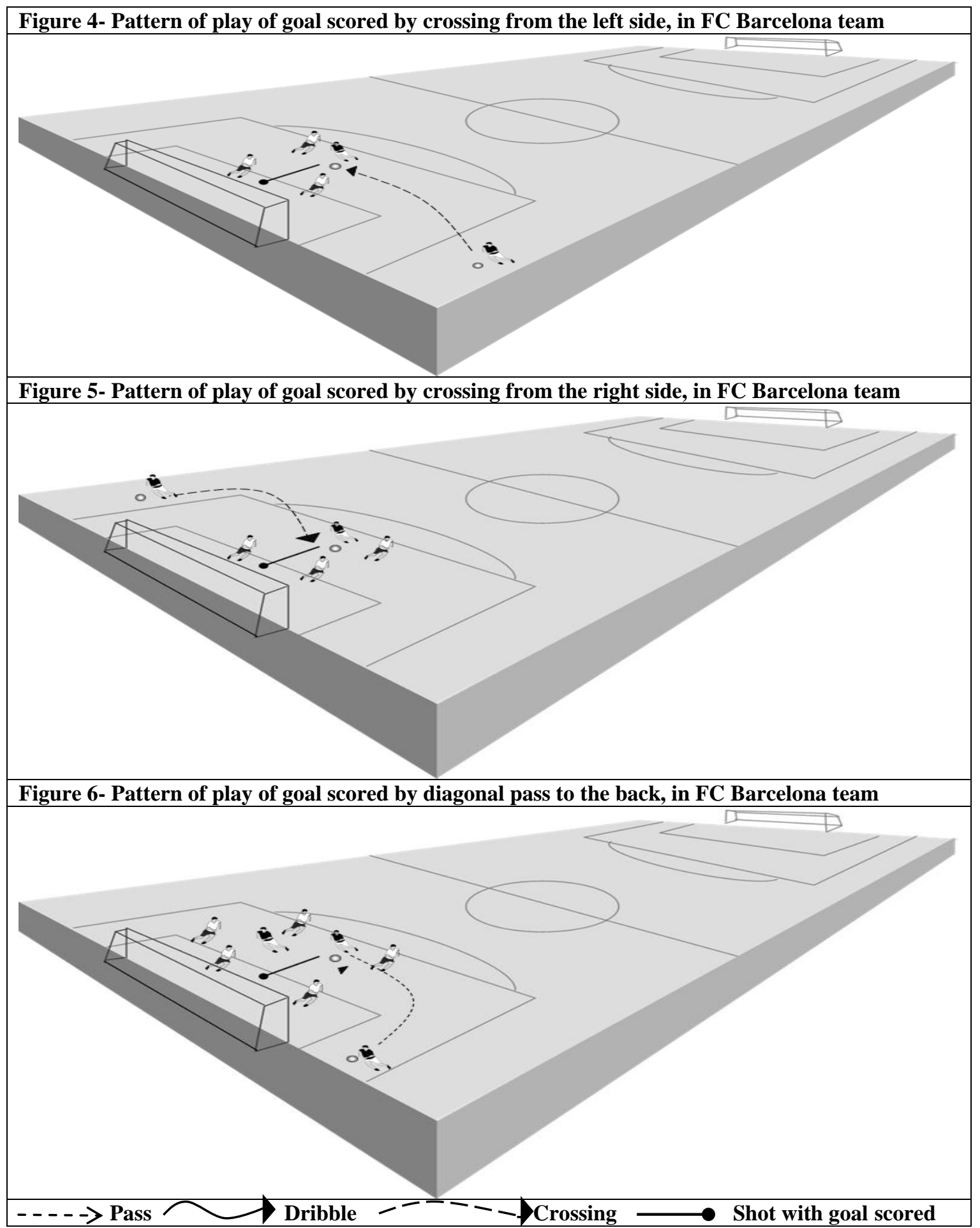

When asked to comment on the results, coaches have considered that this situation is the result of the game model presented by the teams, which have different ideas and players that, despite their huge capacities, present differences at the level of technical execution 
and decision making. The focus, in this case, is on the players from Barcelona's team.

"These are situations which involve decisions, and all is related with decision making, with technical quality, and if we are discussing that Barcelona plays handball with their feet, that is easy to understand. These are players with good decision-making skills, and in those decision areas, they have no difficulties with passing the ball to those in a privileged position." (Coach 6)

"Quality of the players, overall quality of the team, game notion to guide the game model. Take as an example, something really interesting was said: Barcelona players performed the crossing with a high level of effectiveness. And then one might say: Do they have a really striker in the area? No. Do they have a permanent centre forward? No. Do they have only one player to score goals, like most teams where one player scores half of the goals? No. And why? Because the notion of game behind it allows it." (Coach 3 )

When comparing the sequence of behaviours in the counterattack of the three teams, we have concluded that for Inter, the offensive sequences which result in goal, are initiated in their defensive midfield area. Here, most likely, the long pass is performed to the offensive area to allow the last behaviour before the shot with goal scored. A similar tendency is observed on the other teams, which also develop their counterattacks in a progressive action along the field area. This difference is perceived by the coaches interviewed as a result of the different game models each team has, which strategically enhance their players' capacities.

"I believe it is related with the game model, and with the principles that are trained. Of course the game model is also related with the available players and their characteristics. I believe that is a result of the good use of the players characteristics and of the way the team plays according to those characteristics." (Coach 1)

"Inter de Milan's team presents a more vertical game, inviting the opponents to come forward a little bit more in the field, to then use the left space in the back, and try to use it as its own benefit, while Barcelona and Manchester United have more ability to play in the other team's midfield and more capacity to interact with each other, 11 against 11, in the opposing team's midfield." (Coach 3)

\section{Evolutionary tendencies of the game}

From the analysis performed on the interviews, and mostly, from the coaches' opinions regarding this study, we highlight the evolutionary tendencies related to game/training of football. Despite not being an objective of this study, we have considered it to be of importance in this context.

While commenting on some types of ball recovery, coaches have stated that the link between the four moments of the game has been one of the most developing aspects of football in the last years. Nevertheless, it seems that it is not trained with the necessary quality, even among the elite teams, despite of the game differences it can represent. 
"The link between the four moments was something which was not trained $10 / 15$ years ago, and currently it is probably the most challenging area for coaches, because this specific aspect can decide the game. Until a few years ago, we didn't have this notion of what are the moments of connection between the 4 game moments. The link between attack and defence moments can decide the result of a game, and these are the dynamic moments in a game, because training 11 against 11 in continuous attacking or using zone defence, are subjects which are mostly, I don't want to say static but, is repositioning work. It is important to work on the repositioning, and there are still major steps to be taken, because there aren't any exercises... the exercises we have defined to work on this vary from coach to coach, and if we see, there aren't defined exercises for these dynamics. I have no doubt that it is one of the developing game tendencies, because it is essential and we are far from perfect, if we can talk about perfection regarding game moments and set pieces." (Coach 4$)$

"One of the studies we are doing now seeks to understand the recovery moment, and the consequences linked to them. So, the point here is that there is always a strong relationship between the ball recovery moment and the positive sequential possibilities of attack following this recovery. And this needs to be analysed, and there aren't many teams that programmed the ball possession recovery. One of the fundamental developing tendencies in football is the pre-programmed ball possession recovery." (Coach 5)

\section{Conclusions}

Despite the importance attributed to tactical-technical indicators in the assessment of performance in a football game, these are still scarcely used, in favour of the establishment of indicative values of performance based on the obtained results.

This present study sought to contribute a differentiated perspective on the subject of game analysis, using data collection and analysis techniques (sequential analysis and qualitative content analysis) which have not been used frequently in this particular context. The potential value of a combination of these types of analysis is evident. It allows for the detection and analysis of regular behaviour structures (game patterns) which assumes a practical application for coaches. In addition, the content analysis which resulted from the semi-structured interviews, performed with experienced coaches, has served to complement this approach with the know-how of experts in the field. Ultimately, the traditional research undertaken exclusively by scholars is effectively extended.

The resulting utility and added value, of a combination of these two analysis techniques, was confirmed by the understanding demonstrated by the coaches regarding specific game patterns in each of the studied teams. Their analysis was also supported by tactical technical and tactical strategic aspects, by the individual characteristics of each player, and by the approach regarding the developing game/practice tendencies in this sport. These tendencies should be focused mainly on the development of exercises targeting 
the link between all four moments in the game, predefined ball recovery, and the execution of set pieces.

\section{References}

Anguera, M. T., Camerino, O., \& Castañer, M. (2012). Mixed methods procedures and designs for research on sport, physical education and dance. In O. Camerino, M. Castañer \& M. T. Anguera (Eds.), Mixed Methods Research in the Movement Sciences - Case studies in sport, physical education and dance (pp. 3-28). Oxon: Routledge.

Bakeman, R., \& Gottman, J. (Eds.). (1989). Observación de la interacción. Introducción al análisis secuencial. Madrid: Morata.

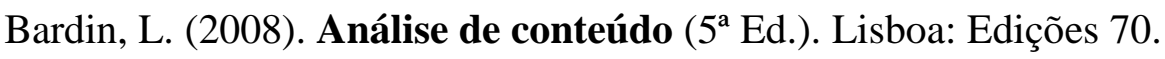

Bloomfield, J., Jonsson, G., Polman, R. C., \& O`Donoghue. (2005). Temporal pattern analysis and its applicability in soccer. In L. Anolli, J. Duncan, M. Magnusson \& G. Riva (Eds.), The hidden structure of interaction: From neurons to culture patterns (pp. 238-250). Amsterdam: IOS Press.

Camerino, O., Chaverri, J., Anguera, M. T., \& Jonsson, G. (2012). Dynamics of the game in soccer: Detection of T-patterns. European Journal of Sport Science, 12(3), 216-224.

Castellano-Paullis, J., \& Hernández-Mendo, A. (2000). Análisis secuencial en el fútbol de rendimiento. Psicothema, 12 (Supl. $\mathrm{n}^{\circ}$ 2), 117-121.

Castelo, J. (Ed.). (2009). Futebol - Organização Dinâmica do jogo. Lisboa: Centro de Estudos de Futebol da Universidade Lusófona de Humanidades e Tecnologia.

Fernandez, J., Camerino, O., Anguera, M. T., \& Jonsson, G. (2009). Identifying and analyzing the construction and effectiveness of offensive plays in basketball by using systematic observation. Behavior Research Methods, 41(3), 719-730.

Flick, U. (2005). Métodos qualitativos na investigação científica. Lisboa: Monitor.

Gregson, W., Drust, B., Atkinson, G., \& Salvo, V. (2010). Match-to-Match variability of high-speed activities in premier league soccer. International Journal of Sports Medicine, 31(4), 237-242.

Heinemann, K. (2003). Introducción a la metodología de la investigación empírica en las ciencias del deporte. Barcelona: Editorial Paidotribo.

Hughes, M., \& Franks, I. (2005). Analysis of passing sequences, shots and goals in soccer. Journal of Sports Sciences, 23(5), 509 - 514.

James, N. (2012). Predicting performance over time using a case study in real tennis. Journal of Human Sport and exercise, 7(2), 421-433.

Lago-Penas, C., Lago-Ballesteros, J., \& Rey, E. (2011). Differences in Performance Indicators between Winning and Losing Teams in the UEFA Champions League. Journal of Human Kinetics, 27, 137-148.

Lago-Penas, Carlos, \& Lago-Ballesteros, Joaquin. (2011). Game location and team quality effects on performance profiles in professional soccer. Journal of Sports Science and Medicine, 10(3), 465-471.

Lapresa, Daniel, Álvarez, Leandro, Arana, Javier, Garzón, Belén, \& Caballero, Valvanera. (2013). Observational analysis of the offensive sequences that ended in a shot by the winning team of the 2010 UEFA Futsal Championship. Journal of Sports Sciences, 31(15), 1731-1739. 
Lapresa, Daniel, Anguera, M. Teresa, Alsasua, Roberto, Arana, Javier, \& Garzón, Belén. (2013). Comparative analysis of T-patterns using real time data and simulated data by assignment of conventional durations: the construction of efficacy in children's basketball. International Journal of Performance Analysis in Sport, 13(2), 321-339.

Lapresa, Daniel, Arana, Javier, Anguera, M. Teresa, \& Garzón, Belén. (2013). Comparative analysis of sequentiality using SDIS-GSEQ and THEME: A concrete example in soccer. Journal of Sports Sciences, 31(15), 1687-1695.

McGarry, T. (2009). Applied and theoretical perspectives of performance analysis in sport: Scientific issues and challenges. International Journal of Performance Analysis in Sport, 9, 128-140.

O'Donoghue, P. (2002). Time-motion analysis of work-rate in English FA Premier League soccer. International Journal of Performance Analysis in Sport, 2, 36-43.

O’Donoghue, P. (2009). Interacting Performances Theory. International Journal of Performance Analysis in Sport, 9, 26-46.

O’Donoghue, P. (Ed.). (2010). Research Methods for Sports Performance Analysis. London: Routledge.

O'Donoghue, P., Rudkin, S., Bloomfield, J., Powell, S., Cairns, G., Dunkerley, A., Davey, P., Gary, P., \& Bowater, J. (2005). Repeated work activity in English FA Premier League soccer. International Journal of Performance Analysis in Sport, 5, 46-57.

Pollard, R., \& Reep, C. (1997). Measuring the effectiveness of playing strategies at soccer. Statistician, 46(4), 541-550.

Sarmento, H., Anguera, M. T., Campaniço, J., \& Leitão, J. (2010). Development and validation of a notational system to study the offensive process in football. Medicina (Kaunas), 46(6), 401-407.

Sarmento, H., Barbosa, A., Anguera, M.T., Campaniço, J., \& Leitão, J. (2013). Regular patterns of play in the counterattack of the FC Barcelona and Manchester United football teams. In D. Peters \& P. O’Donoghue (Eds.), Performance Analysis of Sport IX (pp. 59-66). London: Routledge.

Sarmento, H., Pereira, A., Campaniço, J., Anguera, M.T., \& Leitão, J. (2013). Soccer Match Analysis - Qualitative study with first Portuguese League coaches. In D. Peters \& P. O’Donoghue (Eds.), Performance Analysis of Sport IX (pp. 10-16). London: Routledge.

Sarmento, H., Pereira, A., Matos, N., Campaniço, J., Anguera, M. T., \& Leitão, José. (2013). English Premier League, Spain's La Liga and Italy's Serie's A What's Different? International Journal of Performance Analysis in Sport, 13, 773-789.

Strauss, A., \& Corbin, J. (Eds.). (1990). Basics of qualitative research: Grounded theory procedures and techniques. Newbury Park, CA: Sage. 